\title{
El Repositorio de Activos Digitales (ReA) como herramienta para la difusión de la producción científica del IAPH
}

\author{
María Luisa Loza Azuaga, Carmen Sánchez Galiano | Área de servicios documentales, Centro de Documentación y Estudios, \\ Instituto Andaluz del Patrimonio Histórico
}

URL de la contribución <www.iaph.es/revistaph/index.php/revistaph/article/view/4614>

Desde el 2003, año en el que vio la luz la Declaración de Berlín sobre el acceso abierto (Berlin Declaration on Open Access to Knowledge in the Sciences and Humanities) que proponía el libre acceso al conocimiento, este documento ha sido suscrito por más de 400 instituciones científicas. Con el desarrollo de Internet y la facilidad que nos brinda para hacer pública la información científica ha cambiado la manera en la que la comunidad científica y académica difunde su producción y, en especial, a través de lo que ha venido a denominarse como vía verde, iniciativa que apoya que estos recursos sean almacenados en repositorios digitales.

El IAPH ha impulsado la política de acceso abierto a través de su Programa de actuaciones para el conocimiento abierto incluido en su línea estratégica denominada Posicionamiento activo en el Sistema Andaluz de $\mathrm{I}+\mathrm{D}+\mathrm{i}$, del vigente Plan Estratégico del IAPH. Para dar cumplimiento a este mandato, se impulsa en el año 2016 ReA: Repositorio de Activos Digitales.

ReA se plantea unos objetivos más amplios como son la difusión de la producción científica de su personal,

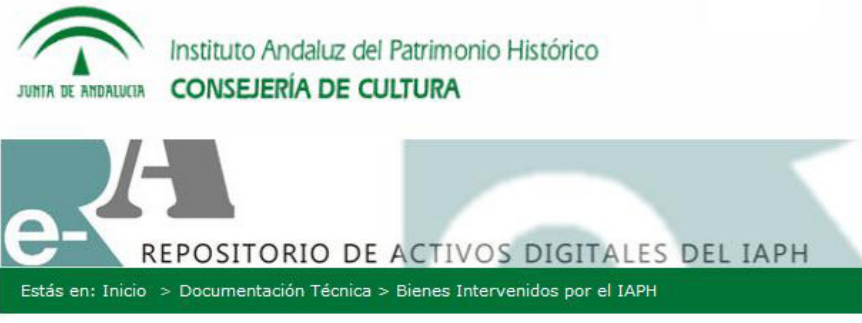

\section{Activos Digitales IAPH}

\author{
https://repositorio.iaph.es
}

la mejora de la transferencia del conocimiento generado por el IAPH, la difusión de la documentación en torno al patrimonio cultural de Andalucía y el uso de esa información por la sociedad, aprovechando la facilidad e inmediatez así como la efectividad que proporciona Internet.

La intervención en el debate la circunscribiremos a ReA como infraestructura de investigación y al papel que desarrolla en la difusión de la producción científica, objetivo para el que los repositorios presentan claras ventajas con respecto a otros medios tradicionales. Una de ellas es la de garantizar un acceso centralizado a la producción científica de todo el personal de la institución y lo que ello supone para la mejora de la visibilidad. Frente a una difusión personalizada, que era la habitual en la mayor parte de la plantilla, en las redes sociales de investigación, como es el caso de Academia.edu o Researchgate, en definitiva, repositorios de carácter comercial que obtienen un beneficio económico suministrando la producción científica en ellas a otros investigadores sin garantizar su preservación, sujeta a los avatares que afectan a este tipo de organizaciones con fines lucrativos.

ReA aporta un marco común para toda la producción científica del personal de la institución, una ventaja por su carácter temático, destinado en exclusiva a un área de conocimiento como es el patrimonio histórico, en la que no son numerosos los repositorios temáticos, facilitando con ello que esta información pueda ser difundida de una manera más eficaz e inmediata. Este carácter temático que avala una mayor visibilidad y con ello un mayor impacto de las investigaciones desarrolladas en el seno de una entidad pionera en este campo con más 


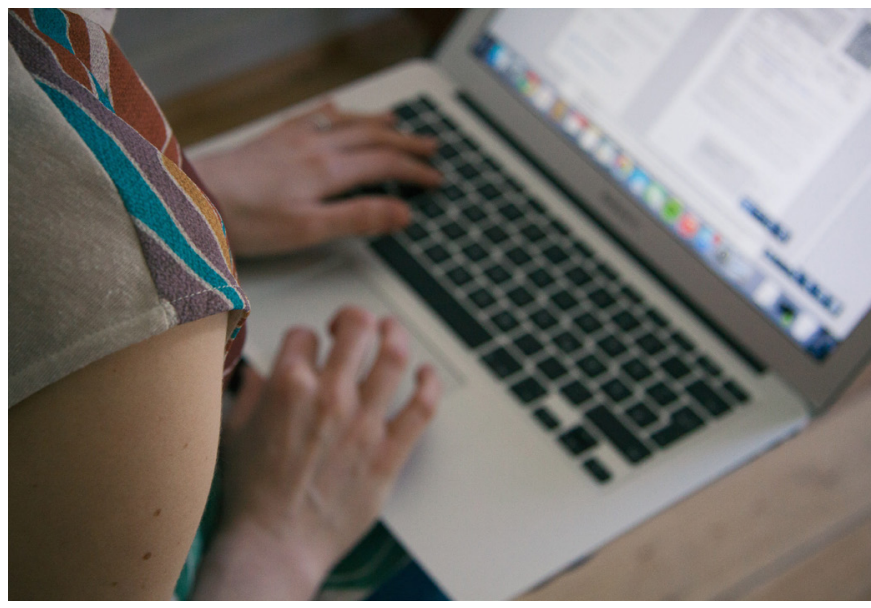

ReA se plantea el uso por la sociedad, gracias a internet, del conocimento científico generado en torno al patrimonio cultural

de treinta años de experiencia y de reconocido prestigio en este ámbito de trabajo.

Un valor añadido a la hora de publicar en los repositorios es la incorporación de indicadores bibliométricos que permiten conocer el impacto de las investigaciones que se desarrollan en el seno de la institución. ReA, hasta el momento, presenta las estadísticas básicas que proporciona Dspace, el sofware libre con el que se administra, pero en fechas próximas se verá complementado con un módulo de unas estadísticas más avanzado, gracias a la colaboración que se ha establecido con la Biblioteca de la Universidad de Sevilla. Así, podremos ofrecer datos más completos, que permitirán contabilizar desde el número total de visitas a un documento hasta las ciudades desde donde se realizan esas visitas o descargas, detalles que pueden ser de gran utilidad no sólo al investigador a la hora de conocer el impacto de su trabajo sino también de gran ayuda para conocer el progreso del propio repositorio.

Otro de los retos que ReA tiene planteado en su plan de gestión 2018-2020 es la mejora de la interoperabilidad como uno de sus mayores valores a la hora de dar visibilidad a la producción académica y científica. Con este fin se tiene prevista la adopción de un firme compromiso con el acceso abierto con la firma de la Declaración de

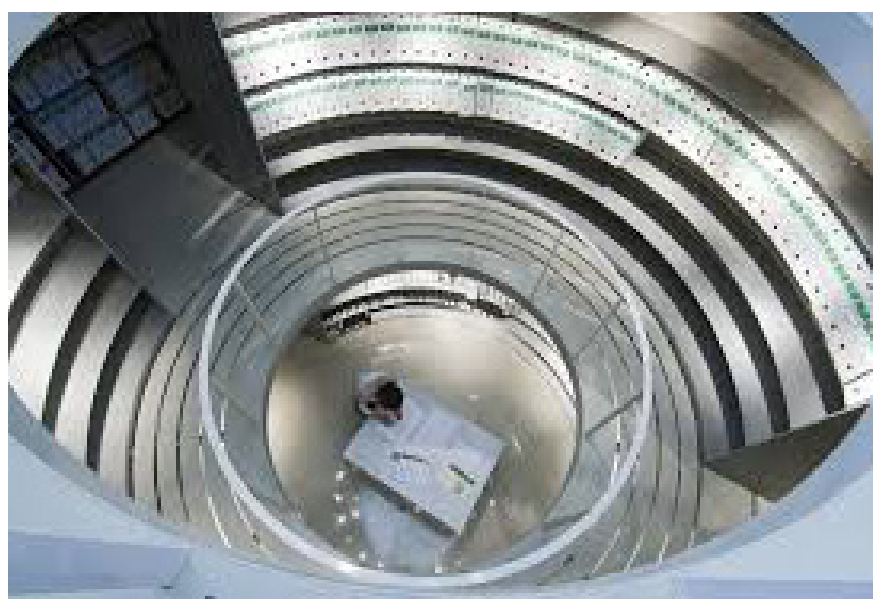

ReA aporta un marco común para toda la producción científica del personal de la institución | foto Fondo Gráfico IAPH (Juan Carlos Cazalla Montijano)

Berlín, uno de los requisitos a la hora de ser incluido en Recolecta, plataforma que agrupa a todos los recolectores científicos españoles. Esta medida se complementa con la publicación de una política de funcionamiento del repositorio, una guía clara y ordenada para la gestión de la comunidad de producción científica de ReA, medida también indispensable para su inclusión. Se ha previsto la agregación a otros directorios; en la actualidad está incluido en Hispana, Europeana, entre los más conocidos, como Opendoar, Re3data, etc., creando una red de repertorios que provean un acceso unificado a los resultados de la investigación del IAPH. 